\title{
Assessment Of Occupational Burnout And Its Correlates Among Medical Doctors in Nepal during COVID-19 pandemic: A cross-sectional study
}

\author{
Pawan Sharma ${ }^{1}$, Swarndeep Singh², Umakanta Tiwari ${ }^{3}$, Rahul Ranjan ${ }^{4}$, Nabin \\ Lekhak $^{3}$, Sajan Acharya ${ }^{5}$
}

1. Assistant Professor, Patan Academy of Health Sciences, School of Medicine, Lalitpur, Nepal 2. Senior Resident, All India Institute of Medical Sciences, New Delhi, India 3. Resident, Patan Academy of Health Sciences, School of Medicine, Lalitpur, Nepal 4. Medical Officer, Patan Academy of Health Sciences, School of Medicine, Lalitpur, Nepal 5. Resident, New York Medical College/Metropolitan Hospital Center, New York, USA

E-mail *Corresponding author : pawan60@gmail.com

\begin{abstract}
Introduction: The current COVID-19 pandemic has increased emotional and physical toll on healthcare workers. The burnout among doctors could be another psychological outcome due to this. Considering the dearth of literature we planned this study with an aim to explore burnout and its correlates among medical doctors of Nepal.

Material And Method: An online survey using a cross-sectional design and purposive sampling was conducted during the lock-down due to COVID-19 pandemic in Nepal. The tools used were basic proforma, Copenhagen Burn out Inventory (CBI) and Perceived Stress Scale (PSS). Descriptive and inferential statistical analysis (bivariate analysis followed by multiple linear regression) was performed with an objective to study prevalence of burnout and its correlates among the medical doctors.
\end{abstract}

Results: The average age of participants was 30.44 years with the majority being male. All the study participants reported moderate to severe level of perceived stress. Around half of them reported moderate to high burnout. The multiple linear regression analyses showed that perceived stress, and working in surgical department were significant correlates for personal and work-related burnout among medical doctors. Additionally, being front-line worker was a significant correlate for client-related burnout.

Conclusion: The burden and severity of burnout and perceived stress reported by the medical doctors during COVID-19 pandemic in the present study, suggests it to be an important mental health issue in Nepal. Suitable interventions for targeting this urgent issue of effectively reducing the burnout are warranted.

Keywords: COVID-19 pandemic; Lock-down; Burnout; Perceived Stress; Medical doctors; Nepal

\section{INTRODUCTION}

Burnout is a work-related hazard or condition that was formally described first in the mid1970s in the United States. ${ }^{1}$ Thereafter, most of the available studies on burnout have been conducted among human service workers. The medical doctors fall into the high-risk category of professionals suffering from burnout as they are exposed to high levels of stress. Also, they often have to deal with a plethora of emotions such as feelings of powerlessness against terminal or refractory illness and its associated losses, grief, fear of becoming ill oneself or dying, facing uncertainty in their routine clinical practice. $^{2}$ Burnout among medical doctors is a global phenomenon and the exact rates reported in the available literature vary by country, medical specialty, practice setting, gender, and career stage. ${ }^{3}$ The novel Coronavirus Disease 2019 (COVID-19) pandemic has resulted in increase of emotional and physical toll on healthcare workers. ${ }^{4}$ The current pandemic has disrupted the sense of order and control among the medical doctors, and is likely to cause 
substantial stress in them over the immediate and short-term period. This is also likely to lead to a higher risk of developing burnout over the long-term. ${ }^{5}$ Most of the published literature focuses on the burnout and stress among the healthcare workers involved in providing direct care to the infected patients during a pandemic. ${ }^{6}$, 7 However, it is of utmost importance to look at the impact of the infectious disease pandemic among the whole fraternity of medical doctors. There is limited available research on burnout among medical doctors from Asian regions, when compared to the West. ${ }^{8}$ This is even more so pronounced in the context of doctors working in the Nepalese setting. As it is well established that culture also plays an important role 8 , a culturally distinguished country like Nepal could possibly have different correlates of burnout among doctors as compared to the western setting or the settings of other Asian countries. In this study, we aimed to explore the burden of occupational burnout among Nepalese doctors and its correlates. This would guide researcher in development of potentially effective interventions aimed at healing the healers.

\section{MATERIAL AND METHOD \\ Study settings and participants}

The data were collected from the doctors working in different settings across Nepal during the COVID-19 pandemic. An online survey using a cross-sectional design and purposive sampling was conducted. The online data collection methodology was chosen due to its benefits like ease of access, cost efficiency, and practical advantages during the time of pandemic. ${ }^{9}$ A link of the survey was sent to the doctors and snow-balling was done. Those doctors willing to participate and provide written informed consent (online) were enrolled in this study. The study was conducted from April 2020 to May 2020 (two months during the lock down period in Nepal).

\section{Instruments:}

\section{i. Basic proforma:}

A semi-structured questionnaire to assess the basic socio-demographic profile of participants (i.e. age, gender, religion, living status, position in the hospital, current working facility and department).

\section{ii. Copenhagen Burnout Inventory (CBI):}

This is a 19-item questionnaire with three subdimensions: personal burnout, work-related burnout, and client-related burnout. ${ }^{10}$ The personal burnout subscale has six items, and it measures the degree of physical and psychological fatigue and exhaustion experienced by a person regardless of their participation in the workforce (i.e. a generic burnout scale). The work-related burnout scale has seven items, and it measures the degree of physical and psychological fatigue related to work. The client-related burnout scale has six items, and it measures the degree of physical and psychological fatigue experienced by people due to their work with clients (e.g. patients, medical students etc.). Twelve items have responses of frequency along a five point Likert scale ranging from '100 (always), 75 (often), 50 (sometimes), 25 (seldom) and 0 (never/almost never). Seven items use response categories according to intensity ranging from 'a very low degree' to 'to a very high degree'. Average scores of 50 to 74 are considered 'moderate', 7599 are high, and a score of 100 is considered severe burnout. ${ }^{11}$ Higher the score higher is the burnout. This scale has been used in previous studies to assess occupational burnout among different group of populations including healthcare professionals with adequate reliability and validity. $12,13,14$

iii. Perceived Stress Scale (PSS):

This is a 10-item, self-report based questionnaire designed to measure the degree to which participants' appraise situations in their lives as stressful. ${ }^{1}$ The items are rated on a five-point Likert scale (0-4), and four items are reverse scored. A higher score on the scale is associated with greater degree of perceived stress. The scores ranging from $0-13$ is considered low stress, scores ranging from 14-26 is considered moderate stress and the scores ranging from $27-$ 40 is considered high perceived stress. This scale has been shown to have acceptable psychometric properties in previous studies. ${ }^{15,16}$

\section{Ethical Issues:}

Informed consent was taken online. Participation in this study was completely voluntary. Participants were made aware that if they decided to stop participating, they could do it at any time. This was an anonymous survey 
and confidentiality of the data obtained was maintained. No incentive was provided for completing the survey. There were no foreseeable risks involved. The anonymous answers were sent to a link where data was stored in a password protected electronic format. No one was able to identify participants and their answers, and no one would know whether or not they participated in the study. This study is a part of another larger project titled "Mental well-being during the COVID 19 pandemic lock-down". The ethical approval has been taken from the Nepal Health Research Council (Ref. no: 2467).

\section{Statistical Analysis:}

The data were analysed using SPSS version 16.0 (Armonk, NY, IBM Corp). Descriptive statistics using mean, standard deviation, frequency and percentage were used to describe the sociodemographic profile, the PSS score, and the three CBI sub-scale scores of study participants. Additionally, median and inter-quartile range was used to describe variables with skewed distribution. The data was checked for normal distribution using Q-Q plots and the Kolmogorov-Smirnov test. The PSS and CBI subscale scores were not normally distributed. Hence, bivariate analysis using appropriate nonparametric inferential statistics were conducted to examine the associations between different continuous (Spearman correlation) and categorical (Mann Whitney U-test or Kruskal Wallis test) study variables, and the three different domains of work-related burnout (three subscale scores of CBI). Three multiple linear regression analyses were performed with variables having significant bivariate relationship entered as independent variables, and the three different domain/ sub-scale wise CBI scores (Personal burnout, Work-related burnout, and Client-related burnout) as the dependent variable. The level of statistical significance was set at $p$-value $<0.05$ for all the tests. There was no missing data encountered.

\section{RESULT}

The majority of participants were male $(n=106$, $74.1 \%)$, and the average age was 30.44 years [Range: 24-46; Standard deviation (SD): 3.58].
The detailed description of study sample is given in Table 1.

Table 1: Descriptive profile of study participants $(\mathrm{N}=143)$

\begin{tabular}{|c|c|}
\hline Study variable & $\begin{array}{l}\text { Mean } \pm \text { SD/ } \\
\text { Median (IQR) or } \\
\text { Frequency } \\
\text { (percentage) }\end{array}$ \\
\hline Age (In years) & $30.44 \pm 3.58$ \\
\hline $\begin{array}{l}\text { Gender: } \\
\text { Male } \\
\text { Female }\end{array}$ & $\begin{array}{l}106(74.1 \%) \\
37(25.9 \%)\end{array}$ \\
\hline $\begin{array}{l}\text { Religion: } \\
\text { Hindu } \\
\text { Buddhist } \\
\text { Christian } \\
\text { Others } \\
\end{array}$ & $\begin{array}{l}131(91.6 \%) \\
8(5.6 \%) \\
2(1.4 \%) \\
2(1.4 \%)\end{array}$ \\
\hline $\begin{array}{l}\text { Marital status: } \\
\text { Not married } \\
\text { Married } \\
\end{array}$ & $\begin{array}{l}75(52.4 \%) \\
68(47.6 \%) \\
\end{array}$ \\
\hline $\begin{array}{l}\text { Current living arrangement: } \\
\text { With family/ friend(s) } \\
\text { Alone }\end{array}$ & $\begin{array}{l}111(77.6 \%) \\
32(22.4 \%)\end{array}$ \\
\hline $\begin{array}{l}\text { Current position: } \\
\text { Medical officer } \\
\text { Medical resident } \\
\text { Consultant } \\
\end{array}$ & $\begin{array}{l}62(43.3 \%) \\
41(28.7 \%) \\
40(28.0 \%)\end{array}$ \\
\hline $\begin{array}{l}\text { Current healthcare facility of work: } \\
\text { Primary level } \\
\text { Secondary level } \\
\text { Tertiary level }\end{array}$ & $\begin{array}{l}8(5.6 \%) \\
32(22.4 \%) \\
103(72.0 \%)\end{array}$ \\
\hline $\begin{array}{l}\text { Department of current working: } \\
\text { Frontline departments } \\
\text { Other medical departments } \\
\text { Surgical departments }\end{array}$ & $\begin{array}{l}65(45.5 \%) \\
52(36.4 \%) \\
26(18.2 \%)\end{array}$ \\
\hline Personal burnout score & $\begin{array}{l}44.75 \pm 21.91 / \\
45.83(29.16-62.50)\end{array}$ \\
\hline Work-related burnout score & $\begin{array}{l}42.88 \quad \pm \quad 23.37 / \\
42.85(25.00-60.71)\end{array}$ \\
\hline Client-related burnout score & $\begin{array}{llr}43.73 & \pm & 23.50 / \\
41.66 & (25.00-62.50)\end{array}$ \\
\hline Perceived stress scale score & $\begin{array}{l}19.84 \pm 2.68 / \\
20.00(18.00-21.00)\end{array}$ \\
\hline
\end{tabular}

All the study participants reported moderate $(n=139,97.2 \%)$ to severe $(n=4,2.8 \%)$ level of perceived stress. The personal burnout severity scores ranged between moderate $(n=56,39.2 \%)$ to high $(n=15,10.5 \%)$ levels for about half of the healthcare professionals, who participated in 
Table 2: Table 2: Bivariate analysis of categorical study variable with three domains of the Copenhagen Burnout Inventory

\begin{tabular}{|c|c|c|c|c|c|c|}
\hline \multirow[b]{2}{*}{ Study variable } & \multicolumn{2}{|c|}{ Personal burnout } & \multicolumn{2}{|c|}{ Work-related burnout } & \multicolumn{2}{|c|}{ Client-related burnout } \\
\hline & $\begin{array}{l}\text { Mean } \\
\text { rank }\end{array}$ & $\begin{array}{l}\text { Statistic } \\
\text { (p-value) }\end{array}$ & $\begin{array}{l}\text { Mean } \\
\text { rank }\end{array}$ & $\begin{array}{l}\text { Statistic } \\
\text { (p-value) }\end{array}$ & $\begin{array}{l}\text { Mean } \\
\text { rank }\end{array}$ & $\begin{array}{l}\text { Statistic } \\
\text { (p-value) }\end{array}$ \\
\hline $\begin{array}{l}\text { Gender: } \\
\text { Male } \\
\text { Female }\end{array}$ & $\begin{array}{l}71.97 \\
72.08 \\
\end{array}$ & $\begin{array}{l}U=1958.0 \\
0(0.98)\end{array}$ & $\begin{array}{l}75.07 \\
63.22 \\
\end{array}$ & $\begin{array}{l}U=1636.0 \\
0(p=0.13)\end{array}$ & $\begin{array}{l}74.49 \\
64.86 \\
\end{array}$ & $\begin{array}{l}\mathrm{U}=1697.0 \\
0(p=0.22)\end{array}$ \\
\hline $\begin{array}{l}\text { Marital Status: } \\
\text { Married } \\
\text { Not married } \\
\end{array}$ & $\begin{array}{l}74.13 \\
70.07 \\
\end{array}$ & $\begin{array}{l}U=2405.0 \\
0(0.55)\end{array}$ & $\begin{array}{l}72.19 \\
71.83 \\
\end{array}$ & $\begin{array}{l}U=2537.0 \\
0(p=0.95)\end{array}$ & $\begin{array}{l}71.50 \\
72.45 \\
\end{array}$ & $\begin{array}{l}U=2516.0 \\
0(p=0.89)\end{array}$ \\
\hline $\begin{array}{l}\text { Living arrangement: } \\
\text { With family/ friend(s) } \\
\text { Alone } \\
\end{array}$ & $\begin{array}{l}72.11 \\
71.63 \\
\end{array}$ & $\begin{array}{l}U=1764.0 \\
0(p=0.95)\end{array}$ & $\begin{array}{l}71.35 \\
73.48\end{array}$ & $\begin{array}{l}U=1728.5 \\
0(p=0.81)\end{array}$ & $\begin{array}{l}71.61 \\
73.34\end{array}$ & $\begin{array}{l}\mathrm{U}=1733.0 \\
0(p=0.83)\end{array}$ \\
\hline $\begin{array}{l}\text { Religion: } \\
\text { Hindu } \\
\text { Buddhist } \\
\text { Christian } \\
\text { Others } \\
\end{array}$ & $\begin{array}{l}70.49 \\
97.81 \\
82.25 \\
57.25\end{array}$ & $\begin{array}{l}\mathrm{H}(3)=3.67 \\
(\mathrm{p}=0.29)\end{array}$ & $\begin{array}{l}70.53 \\
97.56 \\
89.50 \\
48.50 \\
\end{array}$ & $\begin{array}{l}\mathrm{H}(3)=4.22 \\
(\mathrm{p}=0.23)\end{array}$ & $\begin{array}{l}71.91 \\
82.69 \\
44.75 \\
62.50\end{array}$ & $\begin{array}{l}\mathrm{H}(3)=1.51 \\
(\mathrm{p}=0.68)\end{array}$ \\
\hline $\begin{array}{l}\text { Current position: } \\
\text { Medical officer } \\
\text { Medical resident } \\
\text { Consultant }\end{array}$ & $\begin{array}{l}76.44 \\
76.37 \\
60.64 \\
\end{array}$ & $\begin{array}{l}\mathrm{H}(2)=4.19 \\
(\mathrm{p}=0.12)\end{array}$ & $\begin{array}{l}76.84 \\
77.63 \\
58.73 \\
\end{array}$ & $\begin{array}{l}\mathrm{H}(2)=5.72 \\
(\mathrm{p}=0.05)\end{array}$ & $\begin{array}{l}79.13 \\
75.27 \\
57.60\end{array}$ & $\begin{array}{l}\mathrm{H}(2)=6.95 \\
\left(\mathrm{p}=0.03^{*}\right)\end{array}$ \\
\hline $\begin{array}{l}\text { Current healthcare facility of work: } \\
\text { Primary } \\
\text { Secondary } \\
\text { Tertiary }\end{array}$ & $\begin{array}{l}58.88 \\
84.52 \\
69.13 \\
\end{array}$ & $\begin{array}{l}\mathrm{H}(2)=4.23 \\
(\mathrm{p}=0.12)\end{array}$ & $\begin{array}{l}67.68 \\
84.83 \\
68.35 \\
\end{array}$ & $\begin{array}{l}\mathrm{H}(2)=3.96 \\
(\mathrm{p}=0.13)\end{array}$ & $\begin{array}{l}76.81 \\
82.42 \\
68.39 \\
\end{array}$ & $\begin{array}{l}\mathrm{H}(2)=2.92 \\
(\mathrm{p}=0.23)\end{array}$ \\
\hline $\begin{array}{l}\text { Current department of work: } \\
\text { Frontline departments } \\
\text { Surgical departments } \\
\text { Other medical departments }\end{array}$ & $\begin{array}{l}76.47 \\
60.90 \\
83.02\end{array}$ & $\begin{array}{l}H(2)=6.35 \\
\left(p=0.04^{*}\right)\end{array}$ & $\begin{array}{l}79.12 \\
57.89 \\
82.42\end{array}$ & $\begin{array}{l}\mathrm{H}(2)=9.62 \\
\left(\mathrm{p}<0.01^{*}\right)\end{array}$ & $\begin{array}{l}82.10 \\
52.13 \\
86.48\end{array}$ & $\begin{array}{l}\mathrm{H}(2)=19.0 \\
7 \\
\left(\mathrm{p}<0.01^{*}\right)\end{array}$ \\
\hline
\end{tabular}

Table 3: Multiple linear regression analyses for three domains of the Copenhagen Burnout Inventory

\begin{tabular}{|c|c|c|c|c|}
\hline Variables & $\overline{\mathbf{B}}$ & 95\% CI for B & 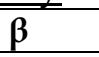 & p-value \\
\hline \multicolumn{5}{|c|}{ Personal burnout (Model $\left.R^{2}=0.0 .246 ; F=15.09, p<0.01^{*}\right)$ : } \\
\hline PSS score & 3.77 & 2.52 to 5.02 & 0.44 & $<0.01^{*}$ \\
\hline Frontline medical department & 4.71 & -2.49 to 11.92 & 0.10 & 0.19 \\
\hline Surgical department & 11.43 & 2.28 to 20.57 & 0.20 & $0.01^{*}$ \\
\hline \multicolumn{5}{|c|}{ Work-related burnout (Model $\left.R^{2}=0.276 ; F=17.66, p<0.01^{*}\right)$ : } \\
\hline PSS score & 4.18 & 2.88 to 5.49 & 0.46 & $<0.01^{*}$ \\
\hline Frontline medical department & 7.18 & -0.35 to 14.71 & 0.15 & 0.06 \\
\hline Surgical department & 12.49 & 2.93 to 22.04 & 0.20 & $<0.01^{*}$ \\
\hline \multicolumn{5}{|c|}{ Client-related burnout (Model $\left.R^{2}=0.271 ; F=12.83, p<0.01^{*}\right)$ : } \\
\hline PSS score & 3.34 & 2.01 to 4.67 & 0.37 & $<0.01^{*}$ \\
\hline Frontline medical department & 13.64 & 4.24 to 23.04 & 0.29 & $<0.01^{*}$ \\
\hline Surgical department & 18.53 & 8.76 to 28.30 & 0.30 & $<0.01^{*}$ \\
\hline Working as Medical officer & 0.14 & -8.35 to 8.64 & 0.003 & 0.97 \\
\hline
\end{tabular}


this study. The work-related burnout severity scores ranged between moderate $(n=47,32.9 \%)$ to high $(n=16,11.2 \%)$ levels for about half of the healthcare professionals, who participated in this study. The client-related burnout severity scores ranged between moderate $(n=47,32.9 \%)$ to high $(n=21,14.7 \%)$ levels for about half of the healthcare professionals, who participated in this study.

The age of study participants did not correlate significantly with any of three CBI subscales. The perceived stress severity represented the PSS scores, showed significant correlations with personal burnout $(\rho=0.47, p<0.01)$, work-related burnout $(\rho=0.49, p<0.01)$, and client-related burnout $(\rho=41, p=0.07)$ scores among study participants. The bivariate analysis assessed the relationship of different categorical study variables with the three different CBI subscale scores (see Table 2). The Kruskal-Wallis test showed that the study participants' current department of working significantly affects their personal burnout $[\mathrm{H}(2)=6.35, \mathrm{p}=0.04]$, workrelated burnout $[\mathrm{H}(2)=9.62, \mathrm{p}<0.01]$, and clientrelated burnout $[\mathrm{H}(2)=19.07, \mathrm{p}<0.01]$ subscale scores on the CBI. The healthcare professionals working in the frontline departments reported significantly greater scores on the personal burnout $\quad(p=0.04)$, work-related burnout $(\mathrm{p}<0.01)$, and client-related burnout $(\mathrm{p}<0.01)$ subscales of the CBI than those working in the other medical speciality departments. Similarly, the healthcare professionals working in the surgical departments reported significantly greater scores on the personal burnout $(p=0.02)$, work-related burnout $(\mathrm{p}<0.01)$, and clientrelated burnout $(p<0.01)$ subscales of the CBI than those working in the other medical speciality departments. The Kruskal-Wallis test showed that the study participants' current position of working significantly affects their client-related burnout $[\mathrm{H}(2)=6.95, \mathrm{p}=0.03]$ subscale score on the CBI. The doctors working as medical officers $(p=0.01)$ reported significantly greater scores on the client-related burnout subscale of the CBI than those working as consultants.

Multiple linear regression analyses were conducted with all the variables showing significant relationship with three different CBI subscale scores in bivariate analysis, entered as independent variables and each CBI subscale score as the dependent variable in three separate regression models (see Table 3). The model for personal burnout was statistically significant ( $F=15.09 ; \mathrm{p}<0.01)$, and explained $24.6 \%$ of the variance in personal burnout CBI subscale score. The perceived stress $(\beta=0.44, p<0.01)$, and currently working in surgical departments $(\beta=$ $0.20, p=0.01$ ) were significant correlates of personal burnout. The model for work-related burnout was statistically significant $(\mathrm{F}=17.66$; $\mathrm{p}<0.01$ ), and explained $27.6 \%$ of the variance in work-related burnout CBI subscale score. The perceived stress $(\beta=0.46, p<0.01)$, and currently working in surgical departments $(\beta=0.20$, $p<$ 0.01 ) were significant correlates of work-related burnout. The model for client-related burnout was statistically significant $(\mathrm{F}=12.83 ; \mathrm{p}<0.01)$, and explained $27.1 \%$ of the variance in clientrelated burnout CBI subscale score. The perceived stress $(\beta=0.37, p<0.01)$, currently working in frontline departments $(\beta=0.29$, $\mathrm{p}<$ $0.01)$, and currently working in surgical departments $(\beta=0.30, p<0.01)$ were significant correlates of client-related burnout.

\section{DISCUSSION:}

The present study aimed to explore the burden of burnout and its correlates among medical doctors practicing in Nepal during the time of COVID-19 pandemic. It was seen that almost all of the respondents had reported moderate to severe perceived stress, and around half of them reported experiencing moderate to severe personal $(49.7 \%)$, work-related $(44.1 \%)$, and client-related (47.6\%) burnout symptoms. Also, the multiple linear regression analyses showed that perceived stress, and working in surgical department were significant correlates for personal and work-related burnout among medical doctors. Additionally, being front-line worker was a significant correlate for clientrelated burnout. The prevalence of burnout was comparable to that reported in most of the available studies from around the world. ${ }^{17}, 18,19$ But the important thing to note here is the current study was conducted during the time of pandemic whereas the studies mentioned above were not conducted in pandemic. Hence, the comparability may not be justified. A systematic review on the burnout symptoms among 
medical doctors in China showed that the prevalence of burnout symptoms ranged between $66.5 \%$ and $87.8 \% .{ }^{8}$ This was higher than that reported in our study. This could be because of the use of different study instruments and methodology across these studies.

Almost hundred percent of respondents reported of having moderate to severe perceived stress that points toward the impact this pandemic has created. The perceived stress score was the most consistent and strongest correlate of personal, work-related and clientrelated burnout among the study participants. This finding is supported by some of the published literature.20, 21 The COVID-19 pandemic has created extraordinary demands from the clinicians, and other sources contributing towards perceived stress experienced by doctors have also increased disproportionately.22 This sudden and disproportionate increase in perceived stress might lead to more burnout among healthcare professionals. ${ }^{23}$ The important management implication here is to note that stress management is likely to be an important strategy in reducing the burnout symptoms experienced by doctors. Another important correlate of burnout was working in surgical departments. There are various reports on the psychological impact of COVID-19 pandemic on the surgeons, 24,25 but a head-to-head comparison with medical and other specialities has not been done till date. This finding could be partly explained on the basis of more risk of exposure to the droplets and body fluids during operation on a patient with unknown or suspected COVID-19 status. This could also be a finding independent of the COVID-19 pandemic related factors, and needs to be further explored through a longitudinal follow-up study. It has been well-established that front line healthcare workers in the COVID-19 pandemic suffer from increased burnout symptoms, psychological stress and other mental health issues. ${ }^{26} \mathrm{~A}$ large scale study conducted in China among the front line nurses showed that half of them complained of moderate to high level of burnout and fear symptoms. ${ }^{27}$ Our study finding that being a doctor working in frontline departments was significantly associated with increased clientrelated burnout is supported by the available literature. ${ }^{28}$ A study conducted in China among
220 physicians and nurses showed that the group working in wards for uninfected patients had reported higher burnout symptoms than those working in the COVID-19 front line ward. ${ }^{29}$ Though this study might not be comparable to our study as we looked at burnout in varied settings the main point to highlight here is the importance of noting that in the face of the COVID-19 pandemic, both front line and usual ward staffs should be considered at an increased risk of experiencing burnout. Thus, with policies and procedures to support and promote the well-being of all healthcare workers should be devised.

Further, regarding the current position of working for the medical doctor, bivariate analysis showed being a medical officer correlated with higher burnout. However, upon multiple regression the burnout experienced by medical doctors was comparable irrespective of their current position of work as a medical officer, medical resident, or consultant.

Regarding the interventions to address the burnout, a meta-analysis of controlled interventions supports the restoration of autonomy; giving doctors flexibility in their work schedule to allow for individual styles of practice and patient interaction as few system solutions that reduced burnout. ${ }^{30}$ As a silver lining to the current pandemic where heath care is at the crisis point there has been a sense of altruism and urgency that has unexpectedly contributed in the restoration of some elements of autonomy, competency, and relatedness which are the components of decreasing burnout among physicians. ${ }^{31}$ These are the findings from the western and high income countries. Hence, this has become imperative to explore among the physicians working in Nepal. This is one of the very few studies from Nepal that has attempted to explore the correlates of burnout among the doctors. We believe this study will work as a baseline in further exploration of other factors related to this issue. Also, we recommend that stress management should be an important component of the overall strategy aimed at addressing this important and highly relevant issue of effectively managing the burnout experienced by healthcare workers.

There are few limitations to our study. The relatively small sample size recruited using a 
non-randomized sampling procedure, limits the generalizability of present study findings. Also, online assessment methods is another limitation. The scales used in current study were not validated for online assessment as well as in context of Nepalese population. We did not look at some of the other important factors reported to affect the burnout experienced by medical doctors in the available literature like clinical experience, history of psychiatric illness, history of chronic medical illness etc. Our study was conducted from April 2020 to May 2020, and during this time-period the number of reported cases of COVID-19 were relatively low in Nepal. This might have underestimated the burden of burnout, and affected the findings of study related to correlates of burnout. Also, we explored the burnout at the time of COVID-19 pandemic, and since as we lack the baseline data among doctors in Nepal we are not able to comment whether pandemic has led to increase in burnout and perceived stress.

\section{CONCLUSION:}

The burden and severity of burnout and perceived stress reported by the medical doctors during COVID-19 pandemic in the present study, suggests it to be an important mental health issue in Nepal. The major correlates of burnout were perceived stress, working in frontline and surgical departments. Future studies are warranted in this area with larger number of doctors and other healthcare professionals such as nurses also included, to confirm and better characterize the correlates of burnout. This would help the policy makers and other stakeholders in developing suitable interventions for targeting this urgent issue of effectively reducing the burnout experienced by the doctors, who are often hailed as corona warriors and hold the key to successful handling of the COVID-19 challenge by the country.

\section{ACKNOWLEDGEMENT: None}

FUNDING: None

CONFLICT OF INTEREST: None

\section{REFERENCES:}

1. Cohen S, Kamarck T, Mermelstein R. A global measure of perceived stress. J Health Soc Behav. 1983 Dec;24(4):385-96.

2. McCue JD. The effects of stress on physicians and their medical practice. $N$ Engl J Med. 1982 Feb 25;306(8):458-63.

3. Lemaire JB, Wallace JE. Burnout among doctors. BMJ [Internet]. 2017 Jul 14 [cited 2020 Jul 9];358. Available from: https://www.bmj.com/content/358/bmj.j3360

4. Sasangohar F, Jones SL, Masud FN, Vahidy FS, Kash $B A$. Provider Burnout and Fatigue During the COVID-19 Pandemic: Lessons Learned From a HighVolume Intensive Care Unit. Anesth Analg [Internet]. 2020 Apr 20 [cited 2020 Jul 9]; Available from: https://www.ncbi.nlm.nih.gov/pmc/articles/PMC71730 87)

5. Dewey C, Hingle S, Goelz E, Linzer M. Supporting Clinicians During the COVID-19 Pandemic. Ann Intern Med. 2020 Mar 20;172(11):752-3.

6. Koh D. Occupational risks for COVID-19 infection. Occup Med Oxf Engl. 2020 Mar;70(1):3-5.

7. Kang L, Li Y, Hu S, Chen M, Yang C, Yang BX, et al. The mental health of medical workers in Wuhan, China dealing with the 2019 novel coronavirus. Lancet Psychiatry. 2020 Mar 1;7(3):e14.

8. Lo D, Wu F, Chan M, Chu R, Li D. A systematic review of burnout among doctors in China: a cultural perspective. Asia Pac Fam Med. 2018 Feb 8;17(1):3.

9. Oseni $K$, Dingley $K$, Hart P. Instant messaging and social networks: The advantages in online research methodology. Int J Inf Educ Technol. 2018;8(1):56-62.

10. Kristensen TS, Borritz M, Villadsen E, Christensen $K B$. The Copenhagen Burnout Inventory: A new tool for the assessment of burnout. Work Stress. $2005 \mathrm{Jul}$ 1;19(3):192-207.

11. Creedy DK, Sidebotham M, Gamble J, Pallant J, Fenwick J. Prevalence of burnout, depression, anxiety and stress in Australian midwives: a cross-sectional survey. BMC Pregnancy Childbirth [Internet]. 2017 Jan 9 [cited 2020 Jul 11];17. Available from: https://www.ncbi.nlm.nih.gov/pmc/articles/PMC52235 36/

12. Rotenstein LS, Torre $M$, Ramos MA, Rosales RC, Guille $C$, Sen $S$, et al. Prevalence of Burnout Among Physicians: A Systematic Review. JAMA. 2018 Sep 18;320(11):1131-50.

13. Winwood PC, Winefield AH. Comparing Two Measures of Burnout Among Dentists in Australia. Int J Stress Manag. 2004;11(3):282-9.

14. Milfont TL, Denny S, Ameratunga S, Robinson E, Merry S. Burnout and Wellbeing: Testing the Copenhagen Burnout Inventory in New Zealand Teachers. Soc Indic Res. 2008 Oct 1;89(1):169-77.

15. Lee E-H. Review of the Psychometric Evidence of the Perceived Stress Scale. Asian Nurs Res. 2012 Dec 1;6(4):121-7. 
16. Taylor JM. Psychometric analysis of the Ten-Item Perceived Stress Scale. Psychol Assess. 2015 Mar;27(1):90-101.

17. Bagaajav A, Myagmarjav S, Nanjid K, Otgon S, Chae YM. Burnout and Job Stress among Mongolian Doctors and Nurses. Ind Health. 2011; advpub:1107280083-1107280083.

18. Doppia M-A, Estryn-Béhar M, Fry C, Guetarni K, Lieutaud $T$, comité de pilotage de l'enquête SESMAT. [Burnout in French doctors: a comparative study among anaesthesiologists and other specialists in French hospitals (SESMAT study)]. Ann Fr Anesth Reanim. 2011 Nov;30(11):782-94.

19. Imo UO. Burnout and psychiatric morbidity among doctors in the UK: A systematic literature review of prevalence and associated factors. BJPsych Bull. 2017 Aug;41(4):197-204.

20. Mitra S, Sarkar AP, Haldar D, Saren AB, Lo S, Sarkar GN. Correlation among perceived stress, emotional intelligence, and burnout of resident doctors in a medical college of West Bengal: A mediation analysis. Indian J Public Health. 2018 Jan 1;62(1):27.

21. Swami MK, Mathur DM, Pushp BK. Emotional intelligence, perceived stress and burnout among resident doctors: an assessment of the relationship. Natl Med J India. 2013 Aug;26(4):210-3.

22. Krystal JH, McNeil RL. Responding to the hidden pandemic for healthcare workers: stress. Nat Med. 2020 May;26(5):639-639.

23. McAlonan GM, Lee AM, Cheung V, Cheung C, Tsang $K W$, Sham PC, et al. Immediate and Sustained Psychological Impact of an Emerging Infectious Disease Outbreak on Health Care Workers. Can J Psychiatry. 2007 Apr 1;52(4):241-7.

24. Karampelias V, Karonis D, Psaroudi V. The psychoemotional impact of COVID-19 on surgical staff working in emergency departments. Eur J Trauma Emerg Surg. 2020 Jun 3;1-3.

25. Kadhum M, Farrell S, Hussain R, Molodynski A. Mental wellbeing and burnout in surgical trainees: implications for the post-COVID-19 era. Br J Surg [Internet]. 2020 May 28 [cited 2020 Jul 10]; Available from:

https://www.ncbi.nlm.nih.gov/pmc/articles/PMC72838 38/

26. Santarone K, McKenney M, Elkbuli A. Preserving mental health and resilience in frontline healthcare workers during COVID-19. Am J Emerg Med. 2020 Jul;38(7):1530-1.

27. Hu D, Kong Y, Li W, Han Q, Zhang X, Zhu LX, et al. Frontline nurses' burnout, anxiety, depression, and fear statuses and their associated factors during the COVID-19 outbreak in Wuhan, China: A large-scale cross-sectional study. EClinicalMedicine. 2020 Jun 27;100424.

28. Barello S, Palamenghi L, Graffigna G. Burnout and somatic symptoms among frontline healthcare professionals at the peak of the Italian COVID-19 pandemic. Psychiatry Res. 2020 Aug 1;290:113129.
29. Wu Y, Wang J, Luo C, Hu S, Lin X, Anderson AE, et al. A Comparison of Burnout Frequency Among Oncology Physicians and Nurses Working on the Frontline and Usual Wards During the COVID-19 Epidemic in Wuhan, China. J Pain Symptom Manage. 2020 Jul 1;60(1):e60-5.

30. Panagioti M, Panagopoulou E, Bower P, Lewith G, Kontopantelis E, Chew-Graham C, et al. Controlled Interventions to Reduce Burnout in Physicians: A Systematic Review and Meta-analysis. JAMA Intern Med. 2017 01;177(2):195-205.

31. Hartzband P, Groopman J. Physician Burnout, Interrupted. N Engl J Med. 2020 Jun 25;382(26):24857. 